\title{
El puerto de Rosario y las propuestas de Juan Canals para su construcción, 1887-1900
}

\author{
Romina Garcilazo \\ Universidad Nacional de Rosario/CONICET
}

\section{Resumen}

En este artículo se analizan los proyectos de Juan Canals para la construcción de la sección norte y sur del puerto de la ciudad de Rosario. Para ello estudiaremos las estrategias económicas y relacionales que Canals desarrolló para llevar a cabo sus propuestas y las causas de su fracaso. Nuestro principal objetivo es - a partir del estudio del presente casodelinear las características que presentó el empresariado de la construcción en la Argentina durante la segunda mitad del siglo XIX. Creemos que nuestro principal aporte será avanzar en la investigación sobre este tipo de empresariado, que ha sido poco explorado por la historiografía nacional.

\section{Palabras claves:}

Rosario, Siglo XIX, Puerto, Empresarios Constructores, Juan Canals

\begin{abstract}
In this article we analyze Juan Canals's projects for the building of Rosario's port north and south areas. We will study the economic and relational strategies that Canals developed to carry on his proposals. We will also look on the causes of this failure. Our main objective is - from the study of this case- outlining the characteristics that had the building business in Argentina during the second half of the 19th century. We believe that our main contribution will be to progress on the research about this kind of business, not very explored in national historiography.
\end{abstract}

\section{Keywords:}

Rosario, 19 th century, Port, Building Business, Juan Canals 


\section{Introducción*}

Hacia fines del siglo XIX la ciudad de Rosario había experimentado a causa de su inserción en el mercado agroexportador un crecimiento inusitado. Sin embargo las obras del puerto que se manifestaban como una necesidad imperiosa, dado el perfil comercial que había adquirido la urbe, reflejaban un significativo retraso. En este contexto uno de los empresarios de la construcción más importantes en el ámbito local, Juan Canals, presentó diferentes proyectos al ejecutivo nacional para la realización de las obras correspondientes al puerto de la ciudad.

Nuestro objetivo en este trabajo es -a partir del presente caso- establecer algunas aproximaciones sobre el funcionamiento y modo de operar que experimentó el empresariado de la construcción hacia fines del siglo XIX. Examinar las estrategias que Canals ensayó para llevar a cabo las obras portuarias y las dificultades por las que atravesó son los dos problemas directrices que guiarán nuestra investigación.

En relación a los objetivos planteados el artículo se estructura en diferentes partes. Una primera donde se planteará un breve estado de la cuestión sobre los estudios empresariales en la Argentina. Luego exploraremos las características generales que presentó la obra pública en nuestro país hacia la década de 1880 y el proceso de acumulación desplegado por el empresario antes mencionado. Mientras que en la segunda parte del escrito avanzaremos sobre el funcionamiento portuario de Rosario hacia fines del siglo XIX y las obras de infraestructura ejecutadas por las empresas particulares y el gobierno nacional. Luego nos abocaremos al análisis de los proyectos de Canals para la construcción de la sección norte y sur del puerto de la ciudad.

\section{Algunas consideraciones generales sobre los estudios empresariales en la Argentina $^{1}$}

\footnotetext{
* Agradezco los comentarios realizados por los evaluadores anónimos de la Revista Páginas

1Puede definirse a la historia de empresas como una disciplina que tiene como objeto de estudio a las empresas y a los empresarios desde una perspectiva histórica. Al interior de la misma pueden distinguirse, en relación al objeto abordado, la historia de empresas y la historia empresarial. Si bien ambas subdisciplinas se complementan de manera constante, poseen su propia especificidad. Mientras que la historia empresarial, que en sus inicios recibió la influencia de Joseph Schumpeter, centra su análisis en el desempeño histórico que determinados empresarios -individuales o colectivos- han tenido. La historia de empresas se focaliza en los cambios experimentados en las organizaciones económicas de las compañías o corporaciones. BARBERO, María Inés, "La historia de empresas en la Argentina: trayectorias y temas de debate en las últimas dos décadas", en GELMAN, Jorge (Coord.), La historia económica en la encrucijada. Balances y perspectivas, Buenos Aires, Prometeo Libros, 2009, pág.153; MARICHAL, Carlos. "Avances recientes en la historia de las grandes empresas y su importancia para la Historia Económica de México", en MARICHAL, Carlos y CERUTTI, Mario (Comp.). Historia de las grandes empresas en México, 1850-1930, México, Fondo de Cultura Económica, 1997, pág. 10; SHUMPETER, Joseph, Teoría del desenvolvimiento económico: una investigación sobre la ganancia, capital, crédito, interés y ciclo económico, México, Fondo de Cultura Económica ,1957 (1911).
} 


\section{Romina Garcilazo}

En las últimas décadas se ha asistido a una persistente producción historiográfica interesada en estudiar la trayectoria de los sectores empresariales en el ámbito latinoamericano durante la segunda mitad del siglo XIX. Algunos especialistas determinaron que el momento formativo de este grupo debe situarse en el siglo XIX y que los mismos orientaron sus actividades económicas hacia la reproducción ampliada del capital. ${ }^{2}$

Un conjunto de investigaciones, para el caso argentino, han analizado las características particulares de este sector concluyendo que los grupos burgueses apostaron a la diversificación de sus actividades económicas, siendo el comercio y las finanzas los dos ámbitos que le permitieron implantarse simultáneamente en los diferentes sectores de la producción y en la actividad especulativa. ${ }^{3}$ Con posterioridad adquirieron gran importancia un conjunto de estudios centrados en las diferentes experiencias empresariales en el ámbito regional y a partir de ellas se ha logrado reformular las hipótesis centrales referidas al proceso de acumulación de este grupo ${ }^{4}$. Los estudios circunscriptos a la ciudad de Rosario, continuaron con esta línea de análisis describiendo los móviles sociales, políticos y económicos de los que se valieron las facciones burguesas para la concreción de sus proyectos empresariales.

Pese al importante avance que ha registrado la historia empresarial, un tema que ha reflejado un menor interés ha sido el referido al empresariado de la construcción. Sobre este tópico, los principales aportes han provenido desde la

\footnotetext{
${ }^{2}$ Véase CERUTTI, Mario y VELLINGA, Menno. Burguesía, e industria en América Latina y Europa Meridional, Madrid, Alianza Editorial ,1989. pág. 290.

${ }^{3}$ Esta hipótesis fue formulada por SÁBATO, Jorge,. La clase dominante en la Argentina moderna. Formación y Características, CISEA Imago Mundi, Buenos Aires, 1991(1988), pág. 280. El mencionado estudio generó una importante discusión en los ámbitos académicos, para ello puede consultarse: SAWERS, Larry,. "Agricultura y estancamiento económico en la Argentina: a propósito de la tesis de Jorge F. Sábato", Ciclos en la Historia, la economía y la sociedad, ${ }^{\circ} 7$, Buenos Aires, 1994; SÁBATO, Jorge,. "Sobre la clase dominante argentina y el estancamiento económico. Réplica a Larry Sawers", Ciclos en la Historia la economía y la sociedad, n8, Buenos Aires, 1995; SARTELLI, Eduardo,. "El enigma de Proteo. A propósito de Jorge F. Sábato, Larry Sawers y el estancamiento de la economía argentina", Ciclos en la Historia, la economía y la sociedad, n 10, Buenos Aires, 1996; PALACIOS, Juan Manuel, "Jorge Sábato y la historiografía rural pampeana: el problema del otro", Entrepasados, $\mathrm{n}^{\circ} 10$, Buenos Aires, 1996. Y el debate Jorge Schvarzer- Roy Hora en Desarrollo Económico Revista de Ciencias Sociales, $\mathrm{n}^{\circ}$ 161, Buenos Aires, 2001. Más recientemente otra importante relectura del libro de Jorge Sábato lo constituye el trabajo de REGALSKY, Andrés,. "Financistas, empresarios y clase dominante en la Argentina antes de 1930", Ciclos en la Historia, la economía y la sociedad, $\mathrm{n}^{\circ} 30$, Buenos Aires, 2005.

${ }^{4}$ CAMPI, Daniel y RICHARD JORBA, Rodolfo. "Las producciones regionales extrapampeanas", en Bonaudo Marta (Directora.). Liberalismo, Estado y Orden Burgués (1852-1880), Vol. IV, Nueva Historia Argentina, Barcelona, 1999, Sudamericana, págs. 363- 422; LANCIOTTI, Norma,. De Rentistas a empresarios. Inversión inmobiliaria y urbanización en la pampa argentina. Rosario 1880/1914, Santa Fe, Ediciones UNL ,2009; HORA, Roy. Los terratenientes de la pampa argentina. Una historia social y política 1860- 1945, Buenos Aires, Siglo Veintiuno Editora Iberoamericana, 2005; REGUERA, Andrea, Patrón de estancias Ramón Santamarina: una biografía de fortuna y poder en la pampa, Buenos Aires, EUDEBA ,2006 y DALLA CORTE, Gabriela, Lealtades firmes. Redes sociales y empresas: la Carlos Casado S.A entre la Argentina y el Chaco Paraguayo (1860-1940), Madrid, CSIC, 2009.
} 


\section{El puerto de Rosario y las propuestas de Juan Canals}

historiografía mexicana donde se han destacado los estudios de Priscillia Connolly, centrados en las empresas constructoras inglesas radicadas en México durante la etapa del porfiriato. En sus investigaciones la autora analizó el modo de operar de las empresas contratistas de obras públicas que lograron convertirse en conglomerados multisectoriales. ${ }^{5}$ Una de las características que revistió este tipo de empresariado, desde la perspectiva de Connolly, ha sido que los contratistas de obras públicas se asemejaron, por su actividad, más un comerciante que a un empresario. Generalmente, estos acudieron a la subcontratación con otras firmas para la obtención de materiales y mano de obra, siendo en algunos casos escasa su intervención en el proceso de transformación. ${ }^{6}$

En el ámbito nacional, las investigaciones sobre este tema han provenido del análisis del pequeño empresariado de la construcción en la ciudad de Mar del Plata durante las primeras décadas del siglo XX. A partir de estos trabajos se ha podido determinar que la rama de la construcción permitió el ascenso social de algunos inmigrantes -en su mayoría de origen italiano- quienes mediante una serie de estrategias, en el que no jugaron un papel menor sus vínculos parentales y amicales, pudieron conformar pequeñas empresas de origen familiar. ${ }^{7}$ Estrictamente para el caso rosarino contamos con los aportes de Norma Lanciotti, quien-analizando el mercado inmobiliario de la ciudad durante el período agroexportador- ha destacado el accionar de algunas empresas constructoras que invirtieron en ese sector. Sobre este tema la historiadora ha destacado que el ámbito de la construcción presentó un elevado grado de informalidad en lo referente a sus formas de organización empresarial y al modo de contratación de la mano de obra. ${ }^{8}$

\section{Las obras públicas en la Argentina durante la segunda mitad del siglo XIX}

En la década de 1880 la Argentina experimentó lo que algunos historiadores han dado en llamar una verdadera revolución urbana. Ello se debió a la metropolización de algunas ciudades como Córdoba, Buenos Aires y Rosario y a la

\footnotetext{
${ }^{5}$ CONNOLLY, Priscilla, El contratista de don Porfirio. Obras públicas, deudas y desarrollo desigual, México, Fondo de Cultura Económica ,1997; CONNOLLY, Priscilla,. "S. Person \& Son: Contratista de Obras Públicas", en MARICHAL, Carlos y CERUTTI, Mario (Comp.). Historia de las Grandes Empresas en México 1850-1930, México, Universidad Autónoma de Nueva León, Fondo de Cultura Económica México, 1997; CONOLLY, Priscilla, "El desagüe del Valle de México. Política infraestructural, contratismo y deuda pública 1890-1900", en KUNTZ FICKER, Sandra y CONNOLLY, Priscilla (Coord.), Ferrocarriles y obras públicas, México, Instituto de Investigaciones José María Luis Mora, 1999.

${ }^{6}$ CONNOLLY, Priscilla, “S. Person \& Son...”Op.Cit., pág. 114.

7 BARTOLUCCI, Mónica, "De artesanos a empresarios. La formación de un pequeño empresariado de la construcción en Mar del Plata, 1900-1935”, Revista Estudios Sociales, n. 20, Santa Fe, 2001, págs.183-197; BARTOLUCCI, Mónica, Pequeños grandes señores. Italianos y estrategias de ascenso social, Mar del Plata, 1910-1930, Buenos Aires, Prometeo Libros, 2009.

${ }^{8}$ LANCIOTTI,.Norma, De rentistas a empresarios...op.cit., pág. 232.
} 


\section{Romina Garcilazo}

construcción de nuevas ciudades y pueblos a lo largo de todo el país. ${ }^{9}$ Estas transformaciones se correspondieron, principalmente, con las modificaciones que implicó para nuestro país el desarrollo del modelo agroexportador. En consonancia con el ideario liberal, la puesta en marcha de este modelo le generó a la clase gobernante el desafío de emprender las obras de infraestructura necesarias para su funcionamiento. Fue por ello que el estado argentino llevó a cabo importantes proyectos para la construcción de un sistema de transporte que permitiera la extracción de mercaderías desde las zonas rurales al área portuaria. En este sentido, el gobierno del presidente Julio A. Roca (1880-1886), tuvo entre sus principales prioridades la construcción del tendido ferroviario, mientras que las obras de infraestructura urbana ocuparon un segundo lugar de importancia. ${ }^{10} \mathrm{Si}$ bien Roca continúo la labor ya emprendida por algunos de sus antecesores, la mayor novedad fue el importante impulso que cobraron durante su gobierno algunas construcciones como consecuencia de la ayuda financiera externa gestionada por el estado nacional. 11

Durante la presidencia de Miguel Juárez Celman (1886-1890) la inversión en obras públicas siguió la curva ascendente. En esos años se crearon a lo largo de todo el país puentes, caminos, escuelas, puertos y se pusieron en marcha edificios de gran envergadura como el Teatro Colón en la ciudad de Buenos Aires. ${ }^{12}$ Asimismo la red ferroviaria continuó desarrollándose a un ritmo acelerado, extendiéndose los ramales a las provincias de Catamarca, Salta y Jujuy. ${ }^{13}$

Algunos analistas han destacado que una de las principales diferencias en materia de obra pública entre el gobierno de Roca y Juárez Celman fue que durante los años 1880-1886 la administración y construcción de ellas estuvo a cargo del estado, mientras que en los años venideros fueron las empresas particulares las que se hicieron cargo de las mismas. ${ }^{14}$

En este contexto de auge económico, las obras portuarias cobraron un gran impulso en el país debido al importante flujo comercial. Ello implicó la necesidad de modernizar y adoptar nuevas tecnologías en esta actividad. Cabe recordar que las ciudades de Rosario y Buenos Aires eran las dos grandes cabeceras nacionales del sistema portuario. Una de las similitudes que presentó la proyección portuaria de estas dos urbes fue que en ambas el ejido urbano estuvo atravesado por los

\footnotetext{
'LIERNUR, Jorge,. "La construcción de un país urbano", en LOBATO, Mirta (Dir.), El Progreso, la modernización y sus límites (1880-1916), Vol. V, Nueva Historia Argentina, Buenos Aires, Sudamericana, 2000, pág. 411.

${ }^{10}$ MARICHAL, Carlos, Historia de la deuda externa de América Latina, México, Alianza Editorial Mexicana, 1988, págs. 154-156.

${ }^{11}$ FERRARI, Gustavo, "La presidencia de Juárez Celman", en FERRARI, Gustavo y GALLO, Ezequiel (comp.), Argentina del Ochenta al centenario, Buenos Aires, Sudamericana, 1980, pág. 189.

12 Ídem.

13 Ídem.

${ }^{14}$ SOMMI, Luis, La Revolución del 90, Buenos Aires, Editorial Moteagudo, 1945, pág. 19.

Durante la presidencia de Juárez Celman se concretó la venta del Ferrocarril Andino y Central Norte y se arrendaron las obras de salubridad de la Capital Federal. Estas medidas generaron un intenso debate en el Congreso de la Nación. Sobre este tema puede verse el texto anteriormente citado de Luis Sommi.
} 


\section{El puerto de Rosario y las propuestas de Juan Canals}

ramales ferroviarios. ${ }^{15}$ Desde el punto de vista técnico -tal como lo han destacado algunos historiadores- uno de los problemas que debieron enfrentar los proyectistas de las nuevas obras fue el dar solución al aumento sostenido del tamaño de los barcos y al creciente tráfico portuario. ${ }^{16}$

Durante este período las obras del puerto de la capital del país -proyectadas por Eduardo Madero- se llevaron a cabo con la asistencia financiera de la casa bancaria Baring Brothers. Esta última autorizó el préstamo para el financiamiento de las mismas luego de que Madero lograra acordar con un especialista británico la supervisión técnica de los trabajos. ${ }^{17}$ Las obras se iniciaron en 1883 y fueron temporariamente suspendidas en el año 1890, como consecuencia de la crisis financiera que asoló al país. Dos años después, el gobierno argentino logró obtener un nuevo empréstito y en 1895 el Congreso de la Nación autorizó un crédito adicional para la culminación de la sección norte. ${ }^{18}$

La fuerte inversión del estado nacional en obra pública posibilitó el desarrollo ferroviario y urbano de la Argentina en un largo plazo. Pero paralelamente generó una importante deuda que, en combinación con otros factores, coadyuvó a la gestación de la crisis financiera de 1890.19 Los especialistas han argumentado que una de las principales fallas del gobierno de Juárez Celman fue que sus políticas no combinaron la puesta en marcha de los proyectos de infraestructura con medidas financieras prudentes. ${ }^{20}$ Asimismo Terry -un reconocido especialista en estas temáticas- también hizo referencia al gasto en obra pública argumentando que éste habría sido necesario para la Argentina, en tanto podría haber acarreado una deuda de aplicación reproductiva. Pero, explicaba Terry, el desmedido gasto en el que los gobiernos argentinos habían incurrido producto de la celebración de diferentes empréstitos y del desembolso que había implicado al país la participación en conflictos bélicos externos y el

\footnotetext{
${ }^{15}$ LIERNUR, Jorge. “La construcción...”.op.cit., págs. 414-415.

${ }^{16}$ La historiografía, principalmente, ha recuperado los proyectos presentados para la construcción del puerto de Buenos Aires y en especial las discusiones que ha suscitado las propuestas de Huergo y Madero. Una de las interpretaciones más difundidas fue la de Scobie quien ha analizado los conflictos económicos y políticos que confluyeron alrededor de cada uno de ellas. Una interpretación alternativa a la hipótesis de este autor es la presentada por Silvestri quien ha examinado las propuestas tomando en consideración sus aspectos técnicos, la relación que cada uno de los mismos guardó con la ciudad y los modos en que las formas de proyección se vincularon con las transformaciones culturales y los conflictos políticos. SCOBIE, James, Buenos Aires del centro a los barrios, 1870-1910, Buenos Aires, Soler Hachette, 1977; SILVESTRI, .Graciela "La ciudad y el río", en LIERNUR, Jorge y SILVESTRI, Graciela. El umbral de la metrópolis. Transformaciones técnicas y culturales en la modernización de Buenos Aires (1870-1930), Buenos Aires, Sudamericana, 1993, pág. 105.

${ }^{17}$ SCOBIE, James, Buenos Aires del centro...op.cit., pág. 107.

18Ídem, pág. 111.

${ }^{19}$ MARICHAL, Carlos, Historia de la deuda externa...op.cit., pág. 158.

Según los datos recogidos por Cortes Conde, durante la presidencia de Juárez Celman los mayores egresos provinieron de los Ministerios de Hacienda e Interior. Destacándose en este último un fuerte gasto en materia de obra pública. CORTÉS CONDE, Roberto, Dinero, deuda y crisis. Evolución fiscal y monetaria en la Argentina, Buenos Aires, Sudamericana, Instituto Torcuato Di Tella, 1989, págs.178-179.

20Ídem, pág. 175.
} 


\section{Romina Garcilazo}

desencadenamiento de rebeliones internas, generaron un desmedido gasto improductivo. ${ }^{21}$

Si bien existen diferentes explicaciones sobre las causas de la debacle económica de 1890- entre las posiciones que han privilegiado los factores internos que posibilitaron la crisis- se encuentran aquellas argumentaciones que atribuyen como una de las principales debilidades del gobierno argentino la extrema dependencia que registraron los bancos oficiales con respecto al endeudamiento externo. Ello se debió, en buena medida, a que el estado financió proyectos de obras públicas con fondos externos. Esto no causó mayores problemas mientras la afluencia del capital externo fue mayor a la salida, pero durante el año 1890 debido al pago de la deuda- se produjo una considerable fuga de divisas. En ese momento los bancos estatales debieron vender sus reservas en oro para poder efectuar los pagos correspondientes a los acreedores externos. Pronto sus divisas se agotaron llevándolos a la bancarrota, hecho que afectó de manera repentina a todo el sistema financiero nacional. ${ }^{22}$

En respuesta a la crisis, el estado argentino tomó un conjunto de medidas para paliar sus efectos. ${ }^{23}$ Apeló a una reestructuración del sistema financiero, aumentó significativamente las tarifas de importación, renegoció la deuda externa y utilizó diferentes mecanismos para reducir el gasto público, por ejemplo, la suspensión de obras públicas. ${ }^{24}$ Como consecuencia de ello, los trabajos del puerto de las ciudades de Buenos Aires y Rosario quedaron paralizados y se suspendieron algunas construcciones como las del Congreso de la Nación. ${ }^{25}$

\section{Juan Canals y su proceso de acumulación, Rosario 1870-1901}

Uno de los miembros más destacados de los sectores burgueses rosarinos, durante la segunda mitad del siglo XIX, fue Juan Canals. Un empresario catalán que se radicó en la ciudad de Rosario en el año 1870. A lo largo de su vida se involucró en una multiplicidad de emprendimientos económicos: desde el comercio

\footnotetext{
21TERRY, José, La crisis 1885-1892, Buenos Aires, Imprenta Viedma, 1893, págs. 54-55.

22MARICHAL, Carlos,, Historia de la deuda externa... op.cit., pág.184.

${ }^{23}$ Existen diferentes posicionamientos teóricos acerca de las causas que han provocado la crisis de 1890. Algunos historiadores han destacado los factores externos que la provocaron mientras que otros han puesto el énfasis en sus causas internas. Uno de los estudios pioneros sobre este tema es el trabajo de José Terry. Recientemente los aportes más importantes respecto a este tema han sido los de Roberto Cortes Conde, Carlos Marichal, Pablo Gerchunoff, Fernando Rocchi y Gastón Rossi. Los trabajos a los que estamos haciendo referencia son los siguientes: TERRY, José. La crisis 18851892...op.cit; CORTES CONDE, Roberto,. Dinero, deuda, crisis...op.cit; MARICHAL, Carlos, Historia de la deuda externa...op.cit; GERCHUNOFF, Pablo, ROCCHI, Fernando y ROSSI, Gastón. Desorden y progreso. Las crisis económicas argentinas1870-1905, Edhasa, Buenos Aires, 2008.

${ }^{24}$ GALLO, Ezequiel y CORTES CONDE, Roberto. La República Conservadora. Historia Argentina, T. V, Buenos Aires, Paidós, 1972.

25PANETTIERI, José,. La crisis de 1890. Historia testimonial de la Argentina. Documentos vivos de nuestro pasado, Buenos Aires, Centro Editor de América Latina, 1984, pág. 14.
} 


\section{El puerto de Rosario y las propuestas de Juan Canals}

mayorista, la industria, las finanzas, la construcción, hasta la adquisición de terrenos urbanos y rurales.

En sus primeros tiempos de residencia en Rosario, Canals fue empleado de escritorio, pero luego comenzó a involucrarse en las distintas actividades económicas que le ofrecía la ciudad. En este sentido, hemos podido determinar que el proceso de acumulación de Canals, originariamente, se sustentó en la actividad comercial, tal como lo evidencia el caso de otros empresarios latinoamericanos y argentinos $^{26}$. A partir de la conformación de su primera sociedad en la década de 1870 denominada Escayola, Canals y Cía.- dedicada a la comercialización de productos de almacén al por mayor- el empresario orientó su ganancia hacia la inversión en tierras urbanas y rurales en la ciudad de Rosario y en la provincia de Córdoba. ${ }^{27}$ Paralelamente se involucró en el ámbito financiero a través de su participación, en calidad de accionista, en el Banco Provincial de Santa Fe. ${ }^{28}$

Si analizamos las características de la actividad comercial de Canals podemos afirmar que él se encontraba inserto en una "red étnica" y "parental" de comercialización ya que la sociedad Escayola, Canals y Cía. poseía una sucursal en la ciudad de Barcelona de donde Canals era oriundo. Entre sus integrantes se encontraban uno de sus cuñados -Joaquín Escayola- y otro de sus familiares Endenace Canals-. ${ }^{29}$ La posibilidad de contar con este núcleo familiar y étnico dedicado a esta actividad resultó estratégica en el marco de un contexto económico favorable, en el que los niveles de intercambio entre Argentina y España registraron una gran intensidad. Esto se debió a la extensión de las vías terrestres y fluviales, a las ventajas comparativas que presentaban las mercaderías importadas y a la existencia de un mercado consumidor de origen español. ${ }^{30}$

\footnotetext{
${ }^{26}$ CERUTTI, Mario y VELLINGA, Menno Burguesía, e industria...op.cit; SÁBATO, Jorge. La clase dominante...op.cit.

${ }^{27}$ Entre algunas de las propiedades adquiridas por Canals durante los primeros años de la década de 1880 se encuentran las siguientes: la mitad de una quinta ubicada en la ciudad de Rosario, la mitad de un terreno de pastoreo de dos leguas cuadradas situado en la localidad de Cruz Alta Córdoba, la mitad de un terreno en el departamento Unión (Córdoba) y una finca en la ciudad de Rosario. Protocolo del Escribano Jacinto Correa, Compra- venta Joaquín Escayola a Juan Canals, 30 de mayo de1882, en Archivo de Protocolos Notariales de la Provincia de Santa Fe, Segunda Circunscripción (en adelante APNPSFSC), fs. 93-96; Protocolo del Escribano Jacinto Correa, Retroventa Escayola, Canals y Cía. a don Alejandro Caldelari, 12 de junio de 1885, en APNPSFSC, fs. 190-193; "Compra-venta", La Capital, 11 de marzo de 1887, Rosario; "Las ventas rápidas", La Capital, 25 de marzo de1887, Rosario.

${ }^{28} \mathrm{En}$ el año 1874 Canals poseía 50 acciones de 100 mil pesos cada una a nombre de la sociedad Escayola, Canals y Cía. Memoria que el directorio provisorio del Banco Provincial de Santa Fe, presenta a los señores accionistas el 10 de setiembre de 1874, Imprenta de Eudoro Carrasco, Rosario, 1874.

${ }^{29}$ Protocolo del Escribano Federico Llobet, Poder especial Juan Canals a Pablo Escayola, 17 de febrero de 1883, en APNPSFSC, fs.28-29.

${ }^{30}$ FERNÁNDEZ, Alejandro. "Los comerciantes españoles de Buenos Aires y las transformaciones en el mercado vitivinícola argentino entre 1880-1935", en Ciclos en la Historia, la economía y la sociedad, ${ }^{\circ} 30$, Buenos Aires, segundo semestre de 2005; FERNÁNDEZ, Alejandro y LLUCH, Andrea. "Comercio y redes de comercialización mayoristas y minoristas en la Argentina de comienzos del siglo XX", en BANDIERI, Susana, BLANCO, Graciela y BLANCO, Mónica (Coord). Las escalas de la historia comparada. Empresas y empresarios. La cuestión regional, Buenos Aires, Miño y Dávila, 2008.
} 


\section{Romina Garcilazo}

Durante la segunda mitad de la década de 1880 y hasta la crisis de 1890, Canals continúo invirtiendo en la actividad comercial debido a que integró diferentes sociedades entre las que se encontraban Canals, Dam y Cía. (1887), Poncio Pons y Cía. (1887), Fernández, Baraldi y Cía. (1887) y Maristany y Cía. (1887). ${ }^{31}$ Pero comenzó a diversificar sus actividades hacia otras ramas de la economía. Por esos años Canals se involucró fuertemente en la actividad especulativa -a través de la compra y venta de terrenos inmobiliarios en la ciudad de Rosario- y en el ámbito de la construcción. Respecto a esta última, hacia 1890 había desembolsado 400 mil pesos moneda nacional para la edificación del Palacio de Justicia y 300 mil pesos más para la construcción de la Cárcel Provincial. ${ }^{32}$ Paralelamente, invirtió en ámbito financiero y al igual que otros burgueses de la época participó de la creación de distintas casas bancarias, como el Banco Sindical del Rosario (1889). Asimismo extendió sus negocios hacia el área del transporte, ya que fue accionista de las empresas Tramways del Oeste (1889) y Ferrocarril Oeste Santafesino (1886). ${ }^{33}$

La trayectoria de Canals, al igual que la de otros empresarios de la época, demuestra que el conjunto de sus empresas no estuvieron totalmente relacionadas. ${ }^{34}$ Sin embargo, existieron algunas vinculaciones entre las principales actividades económicas desarrolladas por el empresario. Algunas de sus estrategias se orientaron a vincular la compra y venta de terrenos urbanos con las obras públicas proyectadas, ya que las cédulas hipotecarias obtenidas en ese ámbito le sirvieron como garantía para sus construcciones. A la vez, los terrenos urbanos eran revalorizados por Canals mediante las obras realizadas. En algunas de nuestras investigaciones hemos concluido que el empresario pavimentó las calles en los lugares donde poseía sus propiedades ${ }^{35}$. Además, Canals complementó la actividad especulativa con la creación del Banco Sindical, entidad

\footnotetext{
${ }^{31}$ Canals invirtió 100 mil pesos nacionales moneda legal para la conformación de la sociedad Canals, Dam y Cía., otros 20 mil pesos nacionales moneda legal para la creación de la sociedad Poncio Pons y Cía., 20 mil pesos nacionales moneda legal a nombre de la sociedad Canals, Dam y Cía. para la constitución de la firma Fernández, Baraldi y Cía. y 10 mil pesos nacionales moneda legal en calidad de socio comanditario con la sociedad Canals, Dam y Cía. para la conformación de la sociedad Maristany y Cía. Contratos de sociedades comerciales T. III, en Archivo del Registro Público de Comercio de Rosario (en adelante ARPCR).

${ }^{32}$ Carta de Juan Canals a Alfredo de Arteaga, Rosario, 4 de febrero de 1890, en Archivo General de la Nación (en adelante AGN), Tribunales Comerciales, f. 48.

${ }^{33}$ Canals poseía 100 acciones de 100 pesos nacionales moneda legal cada una en el Banco Sindical, 900 acciones de 100 pesos nacionales fuertes cada una con la firma Escayola, Canals y Cía. y 100 acciones por el mismo valor a su nombre en la empresa El Ferrocarril Oeste Santafesino. Protocolo del Escribano Javier Munuce, Poder General de la Compañía Ferrocarril Oeste Santafesino a Carlos Casado, 12 de julio de 1886, en APNPSFSC; Estatutos del Banco Sindical, 12 de abril de 1889, en Archivo Histórico de la Provincia de Santa Fe (en adelante AHPSF), Ministerio de Gobierno, Sección Gobierno, fs. 189-201.

${ }^{34}$ BARBERO, María Inés, "Los grupos económicos en la Argentina en una perspectiva a largo plazo (Siglos XIX y XX)”, en JONES, Geoffrey y LLUCH, Andrea (Ed.). El impacto histórico de la globalización en Argentina y Chile. Empresas y empresarios, Buenos Aires, Temas, 2011.

${ }^{35}$ GARCILAZO, Romina, "Proyectos y negocios para una ciudad. El accionar de Juan Canals en la modernización de Rosario hacia fines del siglo XIX", XXII Jornadas de Historia Económica, Río Cuarto, 2010.
} 


\section{El puerto de Rosario y las propuestas de Juan Canals}

cuya operación principal fue la compra, venta y alquiler de propiedades. Por último cabe destacar, que sus edificaciones quedaron integradas al área manufacturera mediante la instalación de una "fábrica" de hornos de ladrillos.

A pesar de la multiplicidad de actividades que Canals desplegó desde su llegada a la Argentina, murió fuertemente endeudado en la ciudad de Buenos Aires, a principios de $1901 .^{36}$

\section{Antecedentes de las obras del puerto de la ciudad de Rosario. ${ }^{37}$}

Para mediados de la década de 1850 el puerto de Rosario era un medio transitorio a través del cual se trasladaban mercaderías -en su mayoría bienes elaborados como artículos de ferretería, loza, diversos productos textiles y comestibles- provenientes de los puertos internacionales y de la ciudad de Buenos Aires. Durante la etapa Confederal algunas provincias del interior del país debieron exportar sus productos mediante el puerto de la ciudad, como consecuencia de las medidas adoptadas durante la presidencia de Justo J. De Urquiza. Entre ellas se destacaron la libre navegabilidad de los ríos y la ley de derechos diferenciales que estableció aranceles más elevados para las mercaderías que provinieron de los otros puertos de la República. Si bien- tal como lo han destacado otros historiadores- el intercambio legal e ilegal con Buenos Aires no desapareció, poco a poco Rosario se convirtió en "una puerta de salida para la producción del interior". 38

Hacia las décadas siguientes el desarrollo del sistema ferroviario -que atravesó la ciudad y cambio de manera radical su fisonomía- coadyuvó a estimular la actividad portuaria. Rosario quedó unida de este modo a las colonias agrícolas del sur santafesino y a las principales ciudades y puertos del país. Cabe destacar que un impulso notable de la actividad portuaria se evidenció como consecuencia

\footnotetext{
${ }^{36}$ Según el expediente sucesorio, Canals al momento de su muerte, sólo poseía algunas propiedades urbanas en la ciudad de Rosario. Que en su totalidad estaban afectadas a la deuda que la sucesión de Canals tenía con el Banco Provincial de Santa Fe y con otros acreedores. Juan Canals su sucesión hoy su concurso, Legajo 9010, Primer cuerpo, en Archivo del Poder Judicial de la Nación (en adelante APJN), fs. 68-69.

${ }^{37}$ Entre algunos de los estudios que han abordado el problema del puerto de la ciudad de Rosario en este período pueden citarse los siguientes trabajos: CICUTTI, Bibiana, PONZINI, Bibiana y GARROFÉ, Miguel. "Construcción del imaginario social hacia fines del siglo XIX. La propuesta de Juan Canals para el puerto de Rosario", III Jornadas de Espacio, Memoria e Identidad, Universidad Nacional de Rosario, octubre de 2002; DE MARCO, Miguel Ángel (h). A cien años de la habilitación de los muelles modernos. El puerto de los rosarinos, Rosario, Ente Administrador Puerto de Rosario, 2006; DE MARCO, Miguel Ángel (h), La batalla por el puerto de Rosario, Buenos Aires, Ciudad Argentina,1999; ENSICK, Oscar,. El Puerto de Rosario. Proceso Histórico, Rosario, U.N.R. Editora, 1998; GOMBOS, Tiberio,"El puerto de Rosario", Revista Historia de Rosario, $\mathrm{n}^{\circ} 13$, junio-enero de 1967; GSCHWIND, Juan, El puerto de Rosario: su evolución histórica. Factores de su progreso, Rosario, Academia Nacional de la Historia, 1953 y HOURCADE, Eduardo, "Rosario, ciudad-puerto en el siglo XIX", en FALCÓN, Ricardo y STANLEY, Myriam (Dir.). La historia de Rosario. Economía y Sociedad, T. I, Rosario, Homo Sapiens Ediciones, 2001.

38VIDELA, Oscar y FERNÁNDEZ, Sandra. "La evolución económica rosarina durante el desarrollo agroexportador", en Ídem, pág. 68.
} 


\section{Romina Garcilazo}

de la Guerra del Paraguay (contienda bélica que enfrentó a Paraguay con Argentina, Brasil y Uruguay, durante los años 1865-1870), Rosario se convirtió en una vía de comunicación mediante la cual eran transportados combustibles -como el carbón- y provisiones para las tropas argentinas y aliadas. ${ }^{39}$

Para tener una idea más acaba del importante crecimiento de la actividad portuaria citamos algunas cifras que resultan por demás de significativas. En 1884 el comercio marítimo había sido doce veces mayor que en 1855, si se tomaba en consideración la cantidad de buques que habían ingresado y salido del puerto. Mientras que el flujo de personas que habían ingresado y salido de él para el mismo año alcanzaba a unas 147. 472.40

Dada esa intensa actividad las obras del puerto se constituyeron en una necesidad imperiosa. En 1878 el poder ejecutivo nacional promulgó una ley mediante la cual se comprometía a contratar a empresas particulares para que llevaran a cabo la construcción de las obras correspondientes al puerto de la ciudad. Tres años después el gobierno acordó con la compañía Rodríguez y Cía. su ejecución. Aunque la empresa logró realizar algunos trabajos, por la lentitud con que los mismos se ejecutaron, el estado le rescindió el contrato respectivo. ${ }^{41}$

Con posterioridad, a fines de 1883, el poder legislativo nacional sancionó una nueva ley en la que se autorizó a la presidencia de la nación a invertir la suma de 2 millones de pesos para la realización de las obras portuarias en Rosario. ${ }^{42}$ Tiempo después, el gobierno nacional llamó a licitación para que se llevaran a cabo los trabajos de la primera sección. Pero ante el escaso número de oferentes el estado decidió que las primeras construcciones se llevarán a cabo mediante la administración del Departamento de Ingenieros de la Nación. Pese a que aquellos trabajos se realizaron de manera parcial hacia mediados de la década de 1880, la construcción de las obras portuarias no había registrado notables mejoras. Sólo se había avanzado en la construcción de algunos muelles privados y en la apertura de un número de bajadas. ${ }^{43}$

Por aquellos años el puerto de la ciudad aún presentaba graves falencias. Las principales dificultades eran la incomodidad que tenían los buques de carga para poder acceder al área portuaria y los escasos avances tecnológicos que se empleaban para realizar las obras correspondientes a la excavación del río. El diario El Municipio, que consideró al puerto como un conjunto de "pocos palos y chapas de zinc que hacen servir de muelles y depósitos" 44 , atribuía esta situación a la irresponsabilidad con que las empresas particulares y el estado nacional habían asumido este problema. Dicho matutino desde sus columnas denunciaba:

\footnotetext{
${ }^{39}$ Ídem, pág. 73.

${ }^{40}$ Los datos han sido tomados de CARRASCO, Gabriel, Descripción geográfica y estadística de la provincia de Santa Fe, Buenos Aires, Stiller \& Lass, 1886, pág. 168.

${ }^{41}$ ENSICK, Oscar, El Puerto de Rosario...op.cit., pág. 11.

42Ídem, págs. 11-12.

${ }^{43}$ DÓCOLA, Silvia. y PAMPINELLA, Silvia. “Imágenes de la ciudad y del río 1850-1910", Revista A y $P$, Rosario Facultad de Arquitectura, Planeamiento y Diseño, UNR, 1995, pág. 16.

${ }^{44}$ El Municipio, 22 de marzo de 1889.
} 


\section{El puerto de Rosario y las propuestas de Juan Canals}

Nadie podrá concebir que el gobierno argentino, después de largos años de haber proyectado y dado comienzo a las obras...no haya podido terminarlas, ni entregar al servicio una sección del segundo puerto de la república...Mientras que en el puerto de Rosario se mueve penosamente un metro de tierra o se eleva una viga por cuenta directa del gobierno, con una subvención o con una garantía, se han decretado y realizado multitud de obras públicas con rapidez asombrosa, en todo el territorio de la república... Jamás el puerto de Rosario ha tenido la virtud de ocupar seriamente la atención del congreso argentino...45

Finalmente, hacia fines de la década de 1880-debido a la necesidad de acelerar el ritmo de los trabajos- el gobierno nacional llamó a licitación para dar término a la primera sección del puerto, convirtiéndose Juan Canals en el adjudicatario. 46

\section{Proyectar en tiempos adversos. Las propuestas de Juan Canals para la construcción del Puerto de la ciudad de Rosario}

Canals, quien ya era un distinguido empresario de la construcción, firmó en 1887 un contrato con el gobierno nacional para la edificación de la primera sección del puerto de Rosario. Estas obras tenían por finalidad culminar dicha sección. En compensación por el desembolso que estos trabajos le implicarían al concesionario, Canals obtendría la exoneración del pago de impuestos de aquellos materiales necesarios para la construcción del puerto provenientes del exterior y recibiría por parte del estado útiles, herramientas de construcción, maquinarias y el muelle denominado de Aldao y Díaz. Como garantía del contrato -que duraría tres años pudiendo ser prorrogado- el empresario depositó la suma de 50 mil pesos en cédulas hipotecarias a nombre del Ministerio del Interior. Tal monto sería retirado por Canals una vez que invirtiera igual cantidad de dinero en la realización de las obras proyectadas. ${ }^{47}$

Con posterioridad el ejecutivo nacional llamó nuevamente a licitación para la construcción de murallones, terraplenes y obras anexas para la segunda sección del puerto de la ciudad. En esta oportunidad los oferentes fueron dos, Canals y la empresa Luis Barbieri y Cía. Pese a que ambas propuestas evidenciaban algunas limitaciones, el Departamento de Ingenieros de la Nación, concluyó que la más beneficiosa era la presentada por el empresario catalán. El proyecto de Canals contemplaba la construcción de un muro, de un acceso para las operaciones de carga y descarga de los buques, la edificación de la aduana y de una subprefectura, de un asilo de inmigrantes y de un conjunto de depósitos para el despacho de

\footnotetext{
${ }^{45}$ El Municipio, 19 de noviembre de 1887.

46República Argentina. Ministerio de Obras Públicas. Inspección General de Navegación y Puertos. Concurso para la construcción y explotación de un Puerto Comercial en la ciudad de Rosario 1900. Documentos Preliminares. Antecedentes Legislativos y Administrativos. Anexo A al Informe General. Archivo Museo Histórico Provincial Dr. Julio Marc, (en adelante AMHPJM), pág. 16. 47Ídem, pág. 17.
} 


\section{Romina Garcilazo}

mercaderías. Además incluía la edificación de una estación de ferrocarriles donde convergerían las líneas férreas ya existentes. El empresario calculaba que los trabajos costarían alrededor de 12 millones de pesos moneda nacional. Este monto era extremadamente menor si se tiene en cuenta que las obras del puerto de la ciudad de Buenos Aires costaron alrededor de los 20 millones de pesos moneda nacional. Como garantía de sus proyectos, al igual que en los contratos anteriores, Canals depositó la suma de 120 mil pesos moneda nacional en cédulas hipotecarias que le serían devueltas una vez que invirtiera igual cantidad de dinero. En compensación por los trabajos -según lo establecido por las leyes nacionales- el empresario obtendría el derecho de cobrar muellaje, eslingaje y almacenaje. ${ }^{48}$ Una vez transcurridos los cuarenta años de la concesión los derechos y edificios pasarían a ser propiedad del ejecutivo nacional. La ampliación de las obras se debió a un pedido del proyectista debido a que Canals adujo que para realizar los trabajos correspondientes a la sección primera del puerto necesariamente debía invadir la segunda sección, que se encontraba a cargo del Gobierno. El 15 de julio de 1890 -a pocos días de estallar la Revolución del Parque, que ocasionó la renuncia del presidente Juárez Celman- por decreto del gobierno nacional, le fue conferido al empresario la ampliación del contrato precedente. ${ }^{49}$ Tal como se verá más adelante, debido a ese particular clima político y económico fue dificultoso realizar las obras portuarias proyectadas. ${ }^{50}$

Para llevar a cabo este último contrato Canals conformó la Sociedad Anónima

Puerto de Rosario de Santa $\mathrm{Fe}^{51}$ y propuso como fiador al empresario Eloy Palacios $^{52}$. Palacios en su carácter de fiador solidario tenía la responsabilidad de

\footnotetext{
${ }^{48}$ ENSICK, Oscar. El Puerto de Rosario...op.cit., pág. 13.

${ }^{49}$ República Argentina. Ministerio de Obras Públicas. Inspección General de Navegación y Puertos. Concurso para la construcción y explotación de un Puerto Comercial...op.cit., pág. 4.

Cabe aclarar que el muelle denominado de Aldao y Díaz, había sido adquirido por estos empresarios mediante una transacción ejecutada con los herederos de la familia de Arón Castellanos. Aquellos muelles finalmente fueron transferidos a la Nación como consecuencia de la imposibilidad que registraron los adquirientes para llevar a cabo la construcción de un emplazamiento que permitiera la circulación de navíos. HOURCADE, Eduardo, "Rosario ciudad-puerto...", op.cit., pág.279.

${ }^{50}$ Para una interpretación de la crisis de 1890 en términos políticos pueden consultarse los siguientes trabajos: ANSALDI, Waldo. "La insurrección de 1890. El parque de los senderos que se bifurcan", Ciudad Futura, n 23-24, Buenos Aires, 1990 y SÁBATO Hilda. "La revolución del 90 ¿prólogo o epílogo?", Punto de vista, n 39, Buenos Aires, 1990.

${ }^{51}$ Dicha sociedad se conformó con un capital inicial de 15 millones de pesos oro, entre sus accionistas se encontraban: Eloy Palacios, Juan Canals, Isidro Canals, Juan Dam, José Preto, Ricardo Parera, Nicasio Vila, Javier Munuce, José Manderola, Carlos Palacios, Blas Oscoide, Poncio Pons, Juan Crespo, Alwin Schneider, Emilio Ortiz, Manuel Beretervide, Lorenzo Gundo, José de Urquiza, Pedro Montero, Inocencio Bustos, Juan Cabanellas, Carlos Blyth, Alfonso Diñas, Francisco Gansul, José Yensen, José Subirá, Manuel Carreras, Rafael Almeirote, Salvador Villalonga y Ángel Artal.

${ }^{52}$ Cabe aclarar que el fiador es el que asume el deber directo frente al acreedor de un tercero de garantizar el cumplimiento de una obligación. La particularidad del fiador solidario es que este carece de los beneficios de excusión y división. GARRONE, José,. Diccionario Manual Jurídico, Buenos Aires, Abeledo- Perrot, Buenos Aires, 1997, Segunda edición, pág. 378.

Palacios, fue remplazado en su carácter de fiador solidario por otro de los principales socios comerciales de Canals, el señor Preto. Con posterioridad fue el mismo Canals el que asumió la obligación de ser el fiador de las obras.
} 


\section{El puerto de Rosario y las propuestas de Juan Canals}

responder ante el gobierno de la nación por los daños y perjuicios que el contratista ocasionara en caso de incumplir con las obligaciones asumidas. ${ }^{53}$

Sin embargo y pese a las buenas intenciones de Canals, las obras proyectadas no pudieron llevarse a cabo. En octubre de 1892, estando ejecutadas sólo una parte de las mismas, el poder ejecutivo al mando del presidente Carlos Pellegrini, debió rescindir el contrato correspondiente a la primera sección del puerto de la ciudad y la solicitud con posterioridad otorgada. El gobierno nacional justificó su decisión afirmando que:

no estaba dispuesto a conceder la prórroga solicitada por Juan Canals para dar principio a la construcción del Puerto Sud de Rosario, por cuanto el mantenimiento por tiempo indefinido, de una concesión de ese género, a favor de una empresa particular, podía importar en lo futuro un obstáculo para el desarrollo del puerto principal, cuya primera sección, construida por cuenta de la Nación, acababa de ser terminada, siendo más bien conveniente, para los intereses fiscales, la rescisión del contrato respectivo. ${ }^{54}$

Durante los años 1892 y 1900 Canals y el gobierno nacional mantuvieron un juicio arbitral para la resolución de este conflicto. En representación del ejecutivo intervino Guillermo Torres, mientras que Alwin Schneider fue elegido como árbitro representante de la empresa concesionaria. ${ }^{55}$ Finalmente y luego de existir divergencias entre el gobierno nacional y el empresario, se acordó pagar a Canals 40.000 pesos moneda nacional por la rescisión de los contratos respectivos a las obras del puerto.

\section{Un análisis de las propuestas de Juan Canals para la construcción del puerto de Rosario: puntos de partida}

Luego de haber realizado una breve descripción de los proyectos presentados por Canals, nos plantearemos algunos ejes orientadores que nos sirvan para analizar el presente caso.

En primer lugar deberíamos preguntarnos por los beneficios que hubiera significado para la ciudad la ejecución de estas obras. Creemos que esta pregunta es pertinente debido a que nos llevará a realizar una valoración sobre las obras proyectadas, desde el punto de vista técnico. En este sentido, creemos que las mismas hubieran implicado la posibilidad de solucionar algunos de los principales problemas que presentaba el puerto. Tal como lo manifestó el ingeniero Huergo en uno de sus informes, este era un medio económico y eficaz para la exportación e

\footnotetext{
${ }^{53}$ Concesión del Puerto a favor de Don Juan Canals, Imprenta Librería y Encuadernación de R. Olivé, Rosario Santa Fe, 1891, en AMHPJM, pág. 29.

${ }^{54}$ República Argentina. Ministerio de Obras Públicas. Inspección General de Navegación y Puertos. Concurso para la construcción y explotación de un Puerto Comercial...op.cit., pág. 5.

${ }^{55}$ Algunos de los puntos más sobresalientes del laudo fueron que se fijó la suma de 500.000 pesos moneda nacional el valor de las obras construidas por Canals. Por su parte el concesionario por la rescisión del contrato debió entregar los materiales adquiridos.
} 


\section{Romina Garcilazo}

importación de productos provenientes de algunas de las provincias del interior del país y de la República del Paraguay. Una de las prioridades que debían presentar las obras -según él- era que los buques pudieran ascender de una manera cómoda y segura al área portuaria para la carga y descarga de mercaderías. Para ello era necesario la extensión de muelles y almacenes de depósitos y la creación de vías que permitieran el rápido acceso a la zona portuaria. Una de las fortalezas que presentó el proyecto de Canals era que intentaba dar solución a cada una de estas problemáticas. El empresario partiendo del mismo diagnóstico que Huergo- proponía la construcción de un murallón que permitiera el atraque de buques. Además, el proyecto contemplaba la concentración en un mismo paraje del movimiento comercial de la ciudad, la utilización de todos los elementos necesarios para facilitar la carga y descarga de buques, la delimitación de un área de estación de carga para los ferrocarriles y la construcción integral de todas aquellas instalaciones necesarias para el funcionamiento del puerto. ${ }^{56}$ Tal como lo manifestó Barabino -miembro del Departamento de Ingenieros de la Nación- el proyecto de Canals incluía "un plan general de puerto con los edificios fiscales, maquinarias y útiles necesarios al fácil movimiento del fuerte comercio... con estaciones de carga y pasajeros para el uso de todas la líneas del ferrocarril"57. Sobre este último punto es importante enfatizar -tal como lo manifestaron Cicutti, Ponzini y Garrofé-58 que la intensión de lograr "organizar las extendidas redes ferroviarias a partir de la instalación de una Estación General de Cargas del Ferrocarril"59 constituyó una de las principales fortalezas del proyecto presentado.

Si inscribimos estas propuestas en la trayectoria empresarial de Canals, nos parece oportuno analizar los beneficios económicos perseguidos por el empresario, la complementariedad de esta propuesta con el resto de sus emprendimientos, las causas de su fracaso y las vinculaciones políticas en las que se valió para obtener las licitaciones.

Desde el punto de vista económico este proyecto- al igual que otras de sus construcciones- le implicó al empresario un importante desembolso de dinero. Para el caso de la construcción de la sección sud del puerto se estimaba en 12 millones de pesos moneda nacional que Canals lograría recuperar a muy largo plazo. Sin embargo el beneficio económico de este emprendimiento, Canals lo obtendría mediante el cobro -durante cuarenta años- de las tarifas de carga y descarga de buques y de muellaje y eslingaje. Pero tal como lo manifestó Barabino ello le generaría a la empresa -tomando en consideración los datos de la Administración de la Aduana en Rosario- una ganancia considerable recién en el último período de la concesión. Si se calculaba que a lo largo de un año pasarían

\footnotetext{
${ }^{56}$ Concesión del Puerto a favor de Don Juan Canals...op.cit., págs. 12-13.

57Ídem, pág., 20.

58 CICUTTI, Bibiana, PONZINI, Bibiana y GARROFÉ, Miguel, "Construcción del imaginario social hacia fines del siglo XIX."...op.cit.

${ }^{59}$ Concesión del Puerto a favor de Don Juan Canals...op.cit, pág.23.
} 


\section{El puerto de Rosario y las propuestas de Juan Canals}

por el puerto cuarenta mil toneladas y que por cada tonelada la empresa recibiría un peso setenta por eslingaje y muellaje, esto le ocasionaría a la misma "una pérdida efectiva"60. Barabino explicaba la decisión del concesionario aludiendo que: "es indudable pues que el interés de la Empresa está en los últimos años de la concesión, en que es de presumir que las entradas serán tales de resarcirlas de los perjuicios del principio y aun dejarle una ganancia que no puede establecerse"61. Del análisis anterior puede deducirse que la ganancia que el empresario obtendría por la realización de las obras no era tan fácil de asegurar ni de calcular. Sin embargo esta dificultad fue tenida en cuenta por Canals ya que una de sus estrategias fue proponer que el puerto fuese dividido en diferentes secciones de modo que se pudieran cobrar más rápidamente las tarifas en cuestión. En una carta que Canals escribió a Alfredo de Arteaga, expresaba:

(...) Me parece muy bien dividir las construcciones del puerto en tres o más secciones porque esto representará para la empresa una gran economía de intereses y mayores seguridades para el prestamista...pues lo que urge es hacer un pedazo del puerto que permita utilizar los ingresos de muellaje, descarga, eslingaje, depósitos..."62

Además uno de los beneficios económicos que el empresario obtendría con la concreción del proyecto del puerto provendría de la obtención de alrededor de ochocientos cuarenta y dos mil metros cuadrados que recibiría como compensación de algunos de los edificios adyacentes. ${ }^{63}$

Por otra parte, creemos que Canals se embarcó en este proyecto ya que el mismo podía complementarse con el resto de sus negocios. La necesidad que poseía el empresario -al igual que otros de los representantes de la burguesía en la ciudad- de contar con un puerto que dinamizara el comercio nacional e internacional fue una de las causas que lo inspiraron a ello. A fines de la década de 1880 -tal como lo hemos mencionado en este escrito- Canals había diversificado sus inversiones aunque un número importante de sus empresas como Canals, Dam y Cía., Maristrany y Cía. y Poncio Pons y Cía. se dedicaban a la comercialización de productos ${ }^{64}$. Además este proyecto se complementaría con otra de las empresas de la cual era accionista: el Ferrocarril Oeste Santafesino. Esta última firma había realizado algunas mejoras para facilitar su acceso al puerto de la ciudad como la construcción de un muelle para la carga y descarga de mercaderías y la proyección de un ramal que llegaba hasta el área portuaria y se conectaba con el Ferrocarril Central Argentino. ${ }^{65}$ Esta operatoria de Canals se asemejó al de otras empresas

\footnotetext{
60 Ídem, pág. 25.

61Ídem.

${ }^{62}$ Carta de Juan Canals a Alfredo de Arteaga, Rosario 8 de mayo de 1890, en AGN, Tribunales Comerciales, f. 97.

${ }^{63}$ Concesión del puerto a favor de don Juan Canals...op.cit., pág. 27.

${ }^{64}$ Eduardo Madero, quien llevó a cabo la construcción del puerto en la ciudad de Buenos Aires, también al igual que Canals era representante de una casa comercial dedicada a la importación y exportación de productos. SCOBIE, James. Buenos Aires del centro a los barrios. 1870-1910, Buenos Aires, Solar, 1977, pág. 95.

${ }^{65}$ CARRASCO, Gabriel, Descripción geográfica y estadística...op.cit, pág. 165.
} 


\section{Romina Garcilazo}

constructoras en México que al mismo tiempo que invertían en la actividad ferroviaria, se embarcaron en la construcción de obras portuarias. ${ }^{66}$

Otra de las líneas de análisis que nos llevan a intentar establecer los motivos que orientaron a Canals a involucrarse en la construcción de las obras del puerto se relaciona con la "amistad" forjada entre él y Alfredo de Arteaga. Las extensas cartas en las que Canals explicó a Arteaga los padecimientos que tuvo para llevar a cabo los trabajos del puerto, las negociaciones que emprendió para hacer efectiva la propuesta y los pedidos de ayuda para que Arteaga mediara con los operadores británicos; nos hacen pensar que el proyecto del puerto era uno de los emprendimientos que ambos tenían en común. Esta hipótesis se vuelve más contundente si tenemos en cuenta que por aquellos años, Arteaga, había establecido negociaciones con empresas y banqueros de origen francés y holandés para instalar molinos harineros y silos para el almacenamiento de granos en la Argentina. ${ }^{67}$ Para la efectivización de este tipo de negocios, el puerto de la ciudad era una necesidad imperiosa.

El proyecto del puerto también se nos presenta como un caso interesante para ver la lógica empresarial de Canals, especialmente, en lo referente a sus patrones de inversión. En este sentido cabe decir que el capital que el empresario puso como garantía de las obras proyectadas, provinieron del sector inmobiliario. Unos años antes la sociedad Canals, Dam y Cía. había protagonizado un escándalo referido a los mecanismos utilizados por esta empresa para la obtención de medio millón de cédulas hipotecarias que habían sido otorgadas por el Banco Hipotecario Nacional. Parte de estas cédulas Canals las puso en garantía para la construcción del puerto de la ciudad.68

Es importante aclarar que las cédulas hipotecarias eran un instrumento que permitían tomar préstamos y prestar dinero. Éstas se convirtieron en un medio eficaz de especulación. Los propietarios de tierras recibían a cambio de las escrituras de sus propiedades los bonos hipotecarios que podían ser negociados y

\footnotetext{
${ }^{66}$ CONNOLLY, Priscilla, “S. \& Person...” op.cit, pág. 111.

${ }^{67}$ Alfredo de Arteaga nació en la ciudad de Montevideo en el año 1840 y murió en un viaje a Europa en 1900. Durante algunos años vivió en la ciudad de Rosario donde pudo llevar a cabo diferentes emprendimientos empresariales. MALPIEDI, Rogelio, Alfredo de Arteaga. Reseña de su vida y de su obra, Santa Fe, 2000, pág. 11.

${ }^{68} \mathrm{La}$ prensa local cuyo principal vocero fue el periódico El Municipio denunció a la empresa de Canals.

Las críticas se orientaron hacia la especulación ejercida para valorizar los terrenos en cuestión y por la acción llevada a cabo por los tasadores que lograron la autorización del préstamo por una cantidad superior a la que el banco estaba autorizado a otorgar. Para un análisis más detallado de este tema véase GARCILAZO, Romina. "Juan Canals y el mercado inmobiliario de la ciudad de Rosario 1886-1890", en BONAUDO, Marta (Dir.) Imaginarios, prácticas de un orden burgués Rosario 1850-1930. Instituciones, conflictos e identidades. De lo "nacional" a lo local, T.II, Rosario, Prohistoria Ediciones, 2010, pág.203.

Con respecto a los mecanismos especulativos llevados a cabo con cédulas hipotecarias, pueden consultarse los trabajos de FRENS, H. S,. Gran Bretaña y Argentina en el siglo XIX, Solar /Hachette, Buenos Aires, 1968, cap. XIII; SÁBATO, Hilda, Capitalismo y ganadería en Buenos Aires: la fiebre del lanar 1850-1890, Buenos Aires, Sudamericana, 1989, cap. VII.
} 


\section{El puerto de Rosario y las propuestas de Juan Canals}

vendidos en la Bolsa de Buenos Aires o en el extranjero. ${ }^{69}$ Existieron diferentes canales a partir de los cuales se emplearon las cédulas, las mismas podían ser utilizadas para adquirir el capital necesario para la producción agrícola o ganadera $^{70}$, para la adquisición de bienes suntuarios por parte de las clases propietarias, para la especulación de tierras o como fue el caso de Canals para la construcción. ${ }^{71}$

Por último, queremos centrarnos en las causas que imposibilitaron a Canals llevar a cabo este emprendimiento. En primer término debe destacarse que su accionar tuvo como escenario principal los efectos económicos que la debacle de 1890 ocasionó en los ámbitos de las finanzas y de la construcción de obras públicas.

En parte debe explicarse el fracaso de las obras por los problemas que tuvo el empresario para lograr el financiamiento de las mismas. A diferencia de otros de sus proyectos este recayó, en su mayor parte, sobre él. El estado sólo se había comprometido a ceder algunas maquinarias y materiales y a exonerar a Canals de los impuestos a los insumos extranjeros. Pero fue el empresario el que debió negociar con los banqueros europeos para lograr la financiación. Podemos acercarnos a aquellas dificultades ya que contamos con un número de cartas personales de Canals donde explicó los padecimientos que sufrió para poder llevar a cabo las obras del puerto. Una de ellas se refirió a que las casas financieras no podían darle el préstamo requerido, debido a que el empresario tenía una abultada deuda con el Banco Inglés. Si bien Canals intentó pagar sus obligaciones, se vio sumamente impedido de obtener recursos. El empresario atribuía esta situación a que en varias oportunidades había recurrido a los buenos oficios del director del Banco Provincial de Santa Fe, Eloy Palacios, en busca de ayuda económica. Pero ahora la situación del banco se lo impedía. ${ }^{72}$ En una de sus cartas el empresario expresó: "El día que regresé a Buenos Aires con la concesión del puerto otorgada a mi favor me presenté a Palacios, lleno de contento a dar la nueva y me recibió ordenándome que suspendiera todo porque el Banco no tenía recursos"73

En conclusión las obras no se llevaron a cabo ya que Canals no pudo asegurar la financiación de las mismas, quedando trunca su ejecución. De este modo la paralización del circuito financiero dio origen a la suspensión del circuito de la construcción. Con respecto a ello nos parece interesante destacar que una de las

\footnotetext{
${ }^{69}$ MARICHAL, Carlos,. Historia de la deuda externa...op.cit, pág. 162.

${ }^{70}$ Cabe destacar aquí la importancia que han adquirido algunos trabajos que se han centrado en el análisis de las políticas crediticias llevadas a cabo por los bancos hipotecarios para el sector rural. Sobre este tema puede consultarse el siguiente estudio: FERRARI, Marcela, "El Banco Hipotecario de la Provincia de Buenos Aires y el estímulo a la producción rural", Anuario del IEHS, n . 10, Tandil, 1995.

${ }^{71}$ FERNS, H.S, Gran Bretaña y Argentina ...op.cit, págs. 422-423.

72 Las relaciones existentes entre el empresario Canals y Eloy Palacios las hemos analizado en otro de nuestros trabajos. Para ello puede verse GARCILAZO, Romina,. "Las redes relacionales de un inmigrante español en el Rosario finisecular. El caso de Juan Canals 1870-1890", Avances del Cesor, $\mathrm{n}^{\circ}$ 7, Rosario, 2010, págs.9-23.

${ }^{73}$ Carta de Juan Canals a Alfredo de Arteaga, Rosario 9 de febrero de 1890, en AGN, Tribunales Comerciales, f. 37.
} 


\section{Romina Garcilazo}

estrategias que ejecutó el empresario, en vista de sus dificultades económicas, fue obtener fondos a través de la negociación con empresas constructoras de origen británico. Aunque esta operatoria no pudo llevarse a cabo, debido a los efectos negativos de la debacle de 1890 en el sistema financiero británico. Sobre este punto el empresario afirmó:

(...) Smithers ha comenzado por los Banqueros para el negocio del Puerto y a mí juicio ha sufrido un gran error, él tenía que comenzar por ver esos grandes centros de empresas constructoras y ellos mismos hubiesen facilitado la parte económica y financiera en condiciones muy favorables para nosotros y no he podido contenerme de telegrafiar pues deseo el éxito de nuestro negocio."74

Por otra parte, el fracaso de la realización de los proyectos provino de las características que presentaban las obras, es decir su magnitud y elevado costo. Pero a diferencia de otra de sus construcciones donde Canals se había visto beneficiado por la benevolencia de los órganos de gobierno -quienes no habían exigido al empresario la finalización de los trabajos en los tiempos estipulados y lo habían autorizado a utilizar materiales más económicos que los establecidos por contrato-75 en esta oportunidad no corrió igual suerte. Por el complejo panorama económico, el gobierno nacional no dio prórroga a la realización de las obras, ni tampoco autorizó a sustituir materiales de menor calidad y precio. Además la política en materia de obra pública ensayada por Pellegrini, es uno de los puntos principales que deben ser tomadas en cuenta para explicar el fracaso de estos proyectos.

Otro de los elementos que los especialistas han tomado para caracterizar el accionar del empresariado de la construcción han sido los vínculos políticos de los que se valieron estos hombres para obtener sus contratos. En estas investigaciones se han podido determinar los estrechos vínculos entre los contratistas y algunas personas destacadas del ámbito público. ${ }^{76}$ Para el caso que estamos analizando si bien es difícil establecer el entramado relacional del que se valió Canals para ganar las licitaciones; estamos en condiciones de afirmar que estaba fuertemente ligado al círculo político de Roca y Juárez Celman. Sobre este tema la prensa de la época quien dirigió importantes críticas hacia aquel empresario como consecuencia de una investigación llevada a cabo por el gobierno nacional en 1890 donde se revelaba que Canals había extraído un importante crédito de manera ilícita del Banco Provincial de Santa Fe durante el juarismo- nos brinda una valiosa información, describiendo el accionar de Canals El Municipio afirmó: “Ahí está Don Juan de cuerpo entero y en amigable consorcio con directores de bancos, ministros,

\footnotetext{
${ }^{74}$ Carta de Juan Canals a Alfredo de Arteaga, 18 de mayo de 1890, en AGN, Tribunales comerciales, f.98.

${ }^{75}$ Expedientes del Concejo Deliberante. Intendencia Municipal, T. II, 1888, en Archivo del Concejo Deliberante de la Municipalidad de Rosario (en adelante ACDMR).

${ }^{76}$ CONNOLY, Priscilla, “S. Person \& Son..."op. Cit., págs. 120-121; SCOBIE, James, Buenos Aires del centro a los barrios...op.cit, págs. 95 y103.
} 


\section{El puerto de Rosario y las propuestas de Juan Canals}

diputados nacionales, y otros personajes que en aquella época representaban la influencia presidencial"77

Sin embargo, algunos otros datos nos llevan a precisar que el empresario habría forjado estrechas relaciones con personajes allegados principalmente al ex presidente Roca y a su hermano Ataliva Tal fue el caso de Gregorio Torres socio de Ataliva, ${ }^{78}$ y hombre vinculado al círculo íntimo del presidente. Torres se destacó entre otras cosas por su accionar en el directorio del Banco de la Provincia de Buenos Aires junto a Antonio Cambaceres, Francisco Bosch y Alberto Casares. ${ }^{79}$ Hacia fines de la década de 1890 Canals estableció junto a él una sociedad comercial, pastoril y ganadera en la ciudad de Buenos Aires que se dedicó, entre otras actividades a la construcción de puentes y puertos. ${ }^{80}$ Probablemente aquellas relaciones entre Canals y Torres se habrían gestado durante la etapa del Iriondismo, donde estos personajes de origen porteño se habían involucrado en el negocio de la compra de tierras rurales en la provincia de Santa Fe y habían forjado relaciones con hombres de esta línea política. ${ }^{81}$ Además el acceso de Canals a estos espacios de poder debe explicarse por las vinculaciones políticas y económicas que el empresario mantuvo con el gobernador de la provincia, Gálvez, quien había mantenido una política de adhesión al gobierno de Juárez Celman. ${ }^{82}$

\section{Consideraciones finales}

En el presente estudio hemos avanzado sobre las estrategias llevadas a cabo por Juan Canals para la construcción del puerto de la ciudad de Rosario y las causas de su fracaso.

Una de las ideas directrices que se desprenden del artículo es que los vínculos y las estrategias económicas que forjó el empresario fueron elementos efectivos pero no suficientes para lograr el éxito de sus proyectos empresariales, que tuvieron como marco principal la crisis económica de 1890. En este sentido la imposibilidad financiera de Canals para obtener el crédito necesario para la concreción de los trabajos -debido a la debacle económica que afectó fuertemente a la banca argentina y británica- y los patrones de inversión desplegados por el

\footnotetext{
${ }^{77}$ El Municipio, 11 de septiembre de 1894.

${ }^{78}$ La sociedad integrada por Ataliva Roca, Gregorio Torres, Marcelino Mezquita y José María Nuñez fundó en 1884 la colonia llamada Ataliva Roca ubicada en el actual departamento Castellanos en la provincia de Santa Fe.

${ }^{79}$ GERCHUNOFF, Pablo, ROCCHI, Fernando y ROSSI, Gastón. Desorden y progreso...op.cit, pág.86.

${ }^{80}$ El Municipio, 20 de diciembre de 1899.

${ }^{81}$ Véase GALLO, Ezequiel,. La pampa Gringa. Colonización agrícola en Santa Fe (1870-1895), Buenos Aires, Edhasa, 2004 (1983), pág. 126.

${ }^{82} \mathrm{En}$ algunos documentos biográficos el empresario reconocía su afinidad política con el doctor Galvez. Pero, concretamente, esta vinculación la podemos visualizar en algunas escrituras de compra y venta de terrenos en la ciudad de Rosario efectuadas por Gálvez, Canals y algunos de sus principales socios como Palacios. Protocolo del escribano Javier Munuce, Venta Don José Gálvez a Don Eloy Palacios, Venta Don Juan Canals a José Gálvez, 3 de enero de 1890, en APNPSFSC, fs.17-18; 24-25.
} 


\section{Romina Garcilazo}

empresario en momentos anteriores a la debacle deben ser tenidos en cuenta para explicar el fracaso de estas propuestas. Sobre este último punto cabe recordar que el empresario en ese fatídico año 90 no tuvo los medios económicos necesarios para hacer frente al importante gasto que sus construcciones le generaron. ${ }^{83}$ Pero por otro lado su inversión el tierras urbanas- negocio que también queda paralizado como consecuencia de la debacle- en combinación con la cantidad de acciones que había adquirido en algunas empresas- que se vieron sumamente afectadas por la situación económica que vivía el país- son otros de los factores que deben ser tenidos en cuenta para explicar el frustrado final que evidenciaron sus proyectos del puerto. ${ }^{84}$

El caso analizado parece ser una de las tantas propuestas truncas que debió enfrentar por aquellos años el segundo puerto de la República. Esperamos que en un futuro próximo, y como consecuencia de nuestra tarea investigativa, poder profundizar aún más sobre algunas de las líneas de argumentación que hemos delineado en esta oportunidad.

\footnotetext{
${ }^{83}$ Según los datos con los que contamos en 1890 la deuda que Canals acarreaba como consecuencia de la ejecución de sus construcciones ascendía a 11.600 .000 pesos moneda nacional (100.000 pesos Palacio de Justicia y 11. 500.000 pesos Puerto).

Carta de Juan Canals a Alfredo de Arteaga, 19 de abril de 1890...op.cit.

${ }^{84}$ En 1890 Canals poseía 2.863 .000 pesos moneda nacional en acciones $(2.000 .000$ pesos en acciones en el Banco Sindical, 463.000 pesos en acciones La Industrial Paraguaya y 400.000 pesos en sociedades varias), mientras que su inversión en bienes inmuebles era de 630.000 pesos $\mathrm{m} / \mathrm{n}$. Ídem.
} 